\title{
Comparison of Clinical, Immunological And Radiological Characteristics In Autoimmune GFAP Astrocytopathy, MOGAD And AQP4-Igg +NMOSD Mimicking Infectious Meningitis As The Initial Manifestation
}

\section{Jun Xiao}

Huazhong University of Science and Technology

\section{Shuo-Qi Zhang}

Huazhong University of Science and Technology

\section{Xin Chen}

Huazhong University of Science and Technology

\section{Yue Tang}

Huazhong University of Science and Technology

\section{Man Chen}

Huazhong University of Science and Technology

\section{Ke Shang}

Huazhong University of Science and Technology

\section{Gang Deng}

Huazhong University of Science and Technology

Chuan Qin

Huazhong University of Science and Technology

Dai-Shi Tian ( $\nabla$ tiands@tjh.tjmu.edu.cn )

Huazhong University of Science and Technology

\section{Research Article}

Keywords: A-GFAP-A, MOGAD, AQP4-IgG + NMOSD, infectious meningeal manifestation, clinical characteristics, immunological characteristics, radiological characteristics.

Posted Date: January 14th, 2022

DOI: https://doi.org/10.21203/rs.3.rs-1250290/v1 
License: (c) (i) This work is licensed under a Creative Commons Attribution 4.0 International License. Read Full License 


\section{Abstract}

Objective: Several autoimmune CNS inflammatory diseases, including autoimmune glial fibrillary acidic protein astrocytopathy (A-GFAP-A), myelin oligodendrocyte glycoprotein antibody-associated disease (MOGAD) and aquaporin-4-immunoglobulin-G-positive neuromyelitis optica spectrum disorders (AQP4IgG+ NMOSD) often presented initially with similar infectious meningitis-like symptoms. However, it was not easy to differentiate them at disease onset without antibody detection. The present study aimed to compare the clinical, immunological and radiological features among the three diseases.

Methods: In our single-center cohorts, 9 A-GFAP-A, 17 MOGAD and 11 AQP4-IgG+ NMOSD patients mimicking infectious meningitis as initial symptoms were retrospectively included. The autoantibodies were detected with cell-based assays. The clinical, immunological and radiological characteristics of the three groups were summarized.

Results: AQP4-IgG+ NMOSD patients were statistically more often in men $(10,90.9 \%, P=0.003)$. Tremor was predominated in A-GFAP-A (4, 44.4\%) over MOGAD (1,5.9\%, P= 0.034$)$ and never found in AQP4$\lg$ +NMOSD (0, $P=0.026)$. The Modified Rankin Score $(m R S)$ at the clinical nadir of diseases was lower in AQP4-IgG+NMOSD (2.2 [IQR, 1-3]) compared to A-GFAP-A (3.7 [IQR, 3-5], P=0.04). On CSF examination, white blood cell count (WBC) was higher in A-GFAP-A (median, 272×106/L [range, 0-1600]) compared to AQP4-IgG+NMOSD (median, 12×106/L [range, 0-48], $P=0.049$ ). Significant increase in CSF protein $(1490.7 \pm 871.2 \mathrm{mg} / \mathrm{L})$, lactic acid $(3.43 \pm 0.81 \mathrm{mmol} / \mathrm{L}), \operatorname{lgg}(130.9 \pm 60.4 \mathrm{mg} / \mathrm{L}), \lg \mathrm{M}(8.6 \pm 6.1 \mathrm{mg} / \mathrm{L})$ and IgA $(23.0 \pm 11.4 \mathrm{mg} / \mathrm{L}$ ) levels in A-GFAP-A was found compared to MOGAD (CSF protein: $606.7 \pm 379.4$ $\mathrm{mg} / \mathrm{L}, \mathrm{P}<0.001$; lactic acid: $2.15 \pm 0.62 \mathrm{mmol} / \mathrm{L}, \mathrm{P}<0.001 ; \mathrm{lgG}: 77.9 \pm 71.3 \mathrm{mg} / \mathrm{L}, \mathrm{P}=0.043 ; \mathrm{lgM}$, $2.7 \pm 2.9 \mathrm{mg} / \mathrm{L}, \mathrm{P}=0.002 ; \operatorname{lgA}, 11.3 \pm 12.1 \mathrm{mg} / \mathrm{L}, \mathrm{P}=0.012$ ) and AQP4-IgG+NMOSD (CSF protein: $441.8 \pm 178.0$ $\mathrm{mg} / \mathrm{L}, \mathrm{P}<0.001$; lactic acid: $2.40 \pm 0.66 \mathrm{mmol} / \mathrm{L}, P=0.003 ; \mathrm{lgG}, 53.2 \pm 30.3 \mathrm{mg} / \mathrm{L}, \mathrm{P}=0.01 ; \mathrm{lgM}, 2.1 \pm 3.9 \mathrm{mg} / \mathrm{L}$, $P=0.003 ; \lg A, 5.2 \pm 5.0 \mathrm{mg} / \mathrm{L}, \mathrm{P}=0.001)$. Over half of the A-GFAP-A patients $(5 / 8,62.5 \%)$ showed small $(<2$ $\mathrm{cm})$, symmetrical lesions in ganglia and thalamus $(5 / 8,62.5 \%)$, but never in MOGAD $(0 \%, P=0.001)$ and AQP4-IgG+NMOSD $(0 \%, P=0.026)$. Diffuse meningeal enhancement was common in A-GFAP-A $(8,88.9 \%)$ compared to MOGAD $(5,29.4 \%, P=0.011)$ and AQP4-IgG+NMOSD $(1 / 6,16.7 \%, P=0.011)$. Acute disseminated encephalomyelitis (ADEM) -like lesions occurred frequently in MOGAD (6/16, 37.5\%) but never in A-GFAP-A and AQP4-IgG+NMOSD ( $P=0.02)$.

Conclusion: Our study demonstrated that several signs including the symptom of tremor, a more severe disease course, higher CSF immunological profiles and ganglia bilateral symmetrical lesions, diffuse meningeal enhancement were distinct features in A-GFAP-A, and ADEM-like lesions occurred only in MOGAD mimicking infectious meningitis as initial symptoms, providing possible clinical implications for patient differential diagnosis.

\section{Introduction}


In recent years, an autoimmune, inflammatory disease entity of the central nervous system (CNS), associated with the demonstration of immunoglobulin $\mathrm{G}(\mathrm{IgG})$ autoantibodies against neuronal surface or glial antigens [1], including autoimmune glial fibrillary acidic protein astrocytopathy (A-GFAP$A$ ), myelin oligodendrocyte glycoprotein associated disease (MOGAD) and aquaporin-4-immunoglobulinG-positive neuromyelitis optica spectrum disorders (AQP4-IgG+NMOSD), has quickly emerged [2-4].

MOG-IgG antibodies are exclusive to the CNS and are expressed on the outer membrane of the myelin sheath of oligodendrocytes $[5,6]$. MOGAD primarily results in demyelination. In contrastAQP4-IgG antibodies target water channels located on perivascular astrocytic foot processes [7], and demyelination in AQP4-IgG ${ }^{+}$NMOSD seems to be a secondary phenomenon following astrocytic damage $[8,9]$. Unlike AQP4-IgG and MOG-IgG antibodies which are locate on the cell membrane, GFAP is the primary component of intermediate filaments, highly expressed in the cytoplasm of mature astrocytes, and plays a vital role in modulating astrocyte shape and motility and regulating the function of synapse [10].

Although major differences among these disease entities have been highlighted in several studies [11-14], overlapping clinical manifestations, especially meningitis-like symptoms with fever, headache, Kernig's sign/nuchal rigidity, and pleocytosis in the cerebrospinal fluid (CSF) [15-17], made them easy to be confused with intracranial infections in lack of detection of antibodies, resulting in wrong management decisions and poor prognosis. Accordingly, the differential diagnosis at an early stage is extremely crucial for treatment choice and prognosis.

To date, direct and comprehensive comparison of clinical, immunological, and radiological presentations and treatment responses in the three diseases presented with meningitis-like symptoms is still lacking, yet it is of importance to the early initiation of correct immunological treatment approaches. Here, we reported 37 patients presented with initial symptoms of fever, headache, nuchal rigidity and high pleocytosis in the cerebrospinal fluid (CSF), mimicking infectious meningitis, but finally diagnosed as distinct inflammatory demyelinating disorders of the central nervous system (CNS) with different glial antibodies including MOG, GFAP and AQP-4. A comparison of the clinical, immunological and radiological features was given, aiming to provide clinical differential clues for the neurologists.

\section{Methods}

\section{Identification of cohorts}

We retrospectively recruited three cohorts of patients mimicking infectious meningitis as initial manifestation admitted to Tongji Hospital, Wuhan, China: 1) patients with A-GFAP-A consecutively seen between March 2019 to March 2021 who were previously reported $(n=9)$ [18]; 2) patients with MOGAD consecutively diagnosed by positive proof of anti-MOG-IgG between May 2016 to December 2019 according to the international diagnostic criteria $(n=17)$ [19] 3) patients with AQP4-IgG ${ }^{+}$NMOSD from September 2016 to June 2019 fulfilled 2015 international diagnostic criteria whose AQP4-IgG were positive $(n=11)[20]$. 
The study was approved by the Ethics Committee of Tongji Hospital (TJ-IRB-20190502). All participants provided written informed consents for the use of their medical records, serum and CSF for research purpose.

\section{Collection of clinical data}

Demographic and clinical data of patients regarding age, sex, disease duration, symptoms and immunotherapy used in the acute phase and response to immunotherapies were reviewed and evaluated by two trained neurologists ( $X C$ and $Y T$ ) from the medical record reviews. Neurologic severity was measured at the nadir of the initial attack and after the acute treatment using the Modified Rankin Scale (mRS) scores. Routine blood and CSF analysis (white blood cell counts, protein, lactate dehydrogenase, lactic acid, oligoclonal bands, IgG index, albumin quotient, IgG, IgM and $\lg A$ ) were performed prior to immunotherapies. The detailed demographic, clinical and CSF laboratory characteristics were summarized in Supplementary Table S1, S2 and S3.

\section{Autoantibody testing}

All enrolled patients underwent serum autoantibody testing and all CSF autoantibody testing was performed by all cases except for one with MOGAD at the time of the acute attack. Anti-GFAP-IgG, antiMOG-IgG and anti-AQP4-IgG were detected using a cell-based assay with full-length GFAP, MOG or AQP4 transfected human embryonic kidney 293 (HEK293) cells as reported. [21-23] Besides, the following autoantibodies of serum and/or CSF were also tested: 1) neurological autoantibodies: N-methyl-Daspartate receptor (NMDAR), glutamic acid decarboxylase-65 (GAD65), antiganglioside 1a (GD1a), dipeptidyl-peptidase-like protein 6 (DPPX), AMPA-type glutamate receptor (AMPAR), gamma-aminobutyric acid receptor A (GABAAR), GABABR, contactin-associated protein-like 2 (Caspr2), IGLON5, metabotropic glutamate receptors (mGluR1, mGluR5); 2) autoantibodies for rheumatic disorder (anti-cyclic citrullinated peptide [CCP], antinuclear antibody [ANA], Double-stranded DNA, Sjögren's syndrome antigen A [SSA] and Sjögren's syndrome antigen B [SSB]).

\section{MRI}

Available neuroimaging (T2-weighted/fluid-attenuated inversion recovery [FLAIR] and T1-postgadolinium sequences of the brain, spinal cord and optic nerve) performed with a 1.5 or 3-Telsa scanner was reviewed independently by an experienced neuroradiologist (SZ) who was blinded to the clinical information. The following features were evaluated: presence of medulla, area postrema, brain parenchymal T2 hyperintense lesions and diffuse T2 lesions in the brainstem $(>75 \%$ of the region involved by visual inspection on axial sequences) and the presence of enhancement in the lesions and meninges. Detailed analysis and representative images were shown in Table 3 and Figure 2.

\section{Statistical analysis}

Statistical analysis was performed by the SPSS Software 24.0 version. Summary statistics were reported as median (range, minimum-maximum), median (interquartile range, IQR) or mean \pm standard deviation 
(SD) for continuous variables compared by Wilcoxon rank sum test and as number (\%) for categorical variables compared by Fisher's exact test. A two-sided $P$ value $<0.05$ was considered statistically significant.

\section{Results}

\section{Demographic and clinical characteristics of the three cohorts}

Thirty-seven patients mimicking infectious meningitis as initial manifestations were included in our single-center cohorts (9 in A-GFAP-A; 17 in MOGAD; 11 in AQP4-IgG ${ }^{+}$NMOSD). Their demographics and clinical characteristics were summarized in Table 1.

Patients with AQP4-IgG ${ }^{+}$NMOSD were statistically less in women $(1,9.1 \%)$ than those with A-GFAP-A (6, $66.7 \%, p=0.017)$ and $\operatorname{MOGAD}(12,70.6 \%, p=0.002)$. There was no significant difference in the median age at disease onset (A-GFAP-A, 39 years [range, 14-48], MOGAD, 32 years [range, 13-61] and AQP4-IgG ${ }^{+}$ NMOSD, 37 years [17-67] respectively, $p=0.454$ ), the median disease duration (A-GFAP-A, 93 days [range, 5-730], MOGAD, 18 days [range, 1-60] and AQP4-IgG ${ }^{+}$NMOSD, 17 days [range, 1-60], $p=0.257$ ) and percentage of the intense unit stay (A-GFAP-A, 2, 22.2\%; MOGAD, 1, 5.9\% and AQP4-IgG+NMOSD, 0, 0\% , $p=0.225$ ) of the three cohorts. The most common symptoms included fever, headache, positive Kernig's sign/ nuchal rigidity and tremor. Fever was less frequent in AQP4-IgG ${ }^{+}$NMOSD $(5,45.5 \%)$ compared to AGFAP-A $(9,100 \% ; p=0.014)$, but not significantly different in MOGAD $(14,82.4 \%, p=0.529)$. Positive Kernig's sign/ nuchal rigidity was less frequent in $\operatorname{MOGAD}(5,29.4 \%)$ and $A Q P 4-\lg G^{+} \operatorname{NMOSD}^{2}, 18.2 \%$, $p=0.668)$ but common in A-GFAP-A $(7,77.8 \%, p=0.038)$. Tremor was predominated in A-GFAP-A $(4,44.4 \%)$ over MOGAD $(1,5.9 \%, p=0.034)$ and not found in AQP4-IgG ${ }^{+} \operatorname{NMOSD}(0, p=0.026)$. Headache did not differ among the three groups.

Among them, three patients with AQP4-IgG ${ }^{+}$NMOSD had coexisting autoimmune diseases including Hashimoto's thyroiditis, Sjogren syndrome and rheumatoid arthritis. None of the patients had a history of neoplasm.

The majority of the patients $(33 / 37,89.2 \%)$ received first-line immunotherapy at acute stage, including intravenous methylprednisolone (IVMP, A-GFAP-A, 5, 55.6\%; MOGAD, 12, 70.6\%; AQP4IgG+NMOSD, 5, 45.5\%, $p=0.438$ ), IVMP and plasma exchange (PLEX, A-GFAP-A, 0; MOGAD, 0; AQP4-IgG ${ }^{+}$ NMOSD, 1, 9.1\%, $p=0.541$ ), IVMP and intravenous immunoglobulin (IVIG, A-GFAP-A, 4, 44.4\%; MOGAD, 2 , 11.8\%; AQP4-IgG ${ }^{+}$NMOSD, 3, 27.3\%, $p=0.199$ ) or the 3 combined (AQP4-IgG+NMOSD, 1, 9.1\%). Among 4 patients ( 3 with MOGAD and 1 with AQP4-IgG ${ }^{+}$NMOSD) whom did not receive immunotherapy due to various reasons, 3 of them remained similar mRS scores as the nadir of diseases (median mRS scores before treatment: 2 [IQR, 0.75-2.75] , median mRS scores after treatment: 1.5 [IQR, 0-2], $p=0.766$ ).

The disability at the nadir of disease as calculated by mRS was less severe in AQP4-IgG+NMOSD (2.2 [IQR, 1-3]) compared to A-GFAP-A (3.7 [IQR, 3-5], $p=0.04)$, but had no significant difference compared to 
MOGAD (2.4 [IQR, 1-3], $p=0.704)$, and the majority were responded well to initial immunotherapy at acute stage (A-GFAP-A, 9, 100\%; MOGAD, 14, 82.4\%; AQP4-IgG+NMOSD, 8, 72.7\%, $p=0.325$ ), as the mRS score decreased among the three cohorts (A-GFAP-A, 1.7 [IQR, 1-3]; MOGAD, 0.9 [IQR, 0-1]; AQP4-IgG ${ }^{+}$NMOSD, 1.5 [IQR, 0.5-2.5]; $p=0.326$ ).

It should be mentioned that 10 patients (A-GFAP-A, 4; MOGAD, 5; AQP4-IgG ${ }^{+}$NMOSD, 1) were initially misdiagnosed as tubercular or viral meningoencephalitis, resistant to empiric anti-tuberculosis or antiviral treatment, and were in partial or complete remission to the immunotherapy.

\section{Laboratory and CSF analysis in the three cohorts}

CSF was available in 34/37 (91.9\%) patients with meningitis as initial manifestations (A-GFAP-A: 9; MOGAD: 16; AQP4-IgG ${ }^{+}$NMOSD: 9), the findings were outlined in Table 2. All patients with A-GFAP-A and MOGAD tested negative for AQP4-IgG, while in the AQP4-IgG ${ }^{+}$NMOSD cohort, 5 of 9 (55.6\%) were tested negative for MOG-IgG. White blood cell count (WBC) in CSF was higher in A-GFAP-A cohort (median, $272 \times 10^{6} / \mathrm{L}$ [range, 0-1600]; reference range, 0-8 $\times 10^{6} / \mathrm{L}$ ) compared to AQP4-IgG ${ }^{+}$NMOSD (median, $12 \times 10^{6} / \mathrm{L}$ [range, $0-48$ ], $p=0.049$ ), but had no significant difference compared to MOGAD cohort (median, $99 \times 10^{6} / \mathrm{L}$ [range, 0-480], $p=0.133$ ). Most patients (A-GFAP-A: 8/9, 88.9\% vs AQP4-IgG ${ }^{+}$NMOSD: 2/9, $22.2 \%, p=0.015$; MOGAD: 12/16, 75\% vs AQP4-IgG+NMOSD: $2 / 9,22.2 \%, p=0.033$ ) had lymphocytepredominant pleocytosis in CSF $\left(>10 \times 10^{6} / \mathrm{L}\right)$ without evidence of bacteria and viral infection. Significant increase in CSF protein level in A-GFAP-A cohort $(1490.7 \pm 871.2 \mathrm{mg} / \mathrm{L})$ was found compared to MOGAD $(606.7 \pm 379.4 \mathrm{mg} / \mathrm{L}, p<0.001)$ and AQP4-IgG ${ }^{+}$NMOSD $(441.8 \pm 178.0 \mathrm{mg} / \mathrm{L}, p<0.001)$. All patients $(100 \%)$ suffered from A-GFAP-A had an increased protein level in CSF (>450 mg/L), and 7 of them $(77.8 \%)$ had marked highly elevated protein levels $(>1000 \mathrm{mg} / \mathrm{L}$ ), significantly more frequent compared to MOGAD (elevated protein level: $8 / 16,50 \%, p=0.012$; marked elevated protein level: $3 / 16,18.8 \%, p=0.009$ ) and AQP4-IgG ${ }^{+}$NMOSD (elevated protein level: 3/9, 33.3\%, $p=0.009$; marked elevated protein level: 0/16, $0 \%, p=0.002)$. CSF lactic acid level in A-GFAP-A cohort $(3.43 \pm 0.81 \mathrm{mmol} / \mathrm{L}$; reference range, $1.1-2.4$ $\mathrm{mmol} / \mathrm{L})$ was significantly higher compared to MOGAD $(2.15 \pm 0.62 \mathrm{mmol} / \mathrm{L}, p<0.001)$ and AQP4-lgG ${ }^{+}$ $\operatorname{NMOSD}(2.40 \pm 0.66 \mathrm{mmol} / \mathrm{L}, p=0.003)$. Elevated CSF LDH $(>40 \mathrm{U} / \mathrm{L})$ and lactic acid $(>2.4 \mathrm{mmol} / \mathrm{L})$ levels in A-GFAP-A group (elevated LDH: 4/9, 44.4\%; elevated lactic acid: 8/9, 88.9\%) were significantly more frequent compared to MOGAD (elevated LDH: $1 / 16,6.2 \%, p=0.040$; elevated lactic acid: $3 / 16,18.8 \%$, $p=0.002$ ), but not significantly different from AQP4-IgG ${ }^{+}$NMOSD (elevated LDH: $2 / 9,22.2 \%, p=0.620$; elevated lactic acid: $4 / 9,44.4 \%, p=0.131)$. No significant difference was observed among the three cohorts for marked WBC count (>50×106/L, A-GFAP-A, 6/9, 66.7\%; MOGAD, 9/16, 56.2\%; AQP4-IgG ${ }^{+}$ NMOSD, 2/9, 22.2\%, $p=0.176$ ) and LDH levels (A-GFAP-A, 53.9 $\pm 37.2 \mathrm{U} / \mathrm{L} ; \mathrm{MOGAD}, 21.7 \pm 13.4 \mathrm{U} / \mathrm{L} ; \mathrm{AQP} 4-$ $\operatorname{lgG}^{+}$NMOSD $\left.45.9 \pm 66.2 \mathrm{U} / \mathrm{L} ; p=0.124\right)$.

Two of 7 (28.6\%) cases of A-GFAP-A was positive for oligoclonal bands (OB), and no patients with MOGAD (0/12 [0\%], $p=0.123)$ and AQP4-IgG ${ }^{+}$NMOSD had OB in CSF $(0 / 7[0 \%], p=0.462)$. CSF analysis showed no significant differences among the three cohorts for IgG index (A-GFAP-A, 0.9 \pm 0.3 ; MOGAD, 
0.7 $\pm 0.1 ;$ AQP4-IgG ${ }^{+}$NMOSD $\left.0.7 \pm 0.1 ; p=0.252\right)$, elevated IgG index ( $>0.7 \%, A-G F A P-A, 4 / 7,57.1 \% ;$ MOGAD, 4/12, 33.3\%; AQP4-lgG ${ }^{+}$NMOSD, 1/7, 14.3\%, $p=0.254$ ), albumin quotient (A-GFAP-A, 13.7 \pm 7.2 ; MOGAD, 8.8 $\pm 8.4 ;$ AQP4-IgG ${ }^{+}$NMOSD $\left.6.6 \pm 2.7 ; p=0.178\right)$ and elevated albumin quotient $(>6.5 \%, A-G F A P-A, 6 / 7$, 85.7\%; MOGAD, 4/12, 33.3\%; AQP4-IgG ${ }^{+}$NMOSD, 3/7, 42.9\%, $p=0.154$ ).

The CSF concentrations of IgG, IgM and IgA in A-GFAP-A cohort (IgG, $130.9 \pm 60.4 \mathrm{mg} / \mathrm{L}$; IgM, $8.6 \pm 6.1 \mathrm{mg} / \mathrm{L} ; \mathrm{lgA}, 23.0 \pm 11.4 \mathrm{mg} / \mathrm{L})$ were significantly higher than MOGAD $(\mathrm{lgG}, 77.9 \pm 71.3 \mathrm{mg} / \mathrm{L}, p=0.043$; $\operatorname{lgM}, 2.7 \pm 2.9 \mathrm{mg} / \mathrm{L}, p=0.002 ; \lg \mathrm{A}, 11.3 \pm 12.1 \mathrm{mg} / \mathrm{L}, p=0.012)$ and AQP4-lgG ${ }^{+} \mathrm{NMOSD}(\operatorname{lgG}, 53.2 \pm 30.3 \mathrm{mg} / \mathrm{L}$, $p=0.01 ; \mathrm{lgM}, 2.1 \pm 3.9 \mathrm{mg} / \mathrm{L}, p=0.003 ; \lg A, 5.2 \pm 5.0 \mathrm{mg} / \mathrm{L}, p=0.001$ ) (see in Figure.1). Elevated IgG level (>58.6mg/L) favored A-GFAP-A (9/9, 100\%) over MOGAD (6/16, 37.5\%, $p=0.003)$ and AQP4-IgG ${ }^{+}$NMOSD $^{2}$ $(2 / 9,22.2 \%, p=0.002)$. Elevated IgA level $(>4.4 \mathrm{mg} / \mathrm{L})$ was less frequent in AQP4-lgG ${ }^{+} \mathrm{NMOSD}(2 / 9,22.2 \%)$ than A-GFAP-A $(9 / 9,100 \%, p=0.002)$ and MOGAD $(11 / 16,68.8 \%, p=0.041)$. Elevated IgM level $(>7.0 \mathrm{mg} / \mathrm{L})$ did not differ among the three groups (A-GFAP-A, 4/9, 44.4\%; MOGAD, 2/16, 12.5\%; AQP4-IgG ${ }^{+}$NMOSD, $1 / 9,11.1 \% ; p=0.172)$.

Tests for other neural autoantibodies were detected in 4 patients (A-GFAP-A, 1, DPPX in serum; MOGAD, 2, GD1a in serum and NMDAR-IgG in CSF; AQP4-Ig G ${ }^{+}$NMOSD, 1, GD1a in serum). Serum autoantibodies against ANA and SSA in patients with AQP4-IgG ${ }^{+}$NMOSD (ANA, 6/8, 75\%; SSA, 5/8, 62.5\%) was significantly more frequent than A-GFAP-A (ANA, 0/7, $0 \%, p=0.007$; SSA, $0 / 7,0 \%, p=0.026$ ) and MOGAD (ANA, $1 / 7,14.3 \%, p=0.041$; SSA, $0 / 7,0 \%, p=0.026$ ). There was no significant difference in serum autoantibodies against SSB among the three cohorts (A-GFAP-A, 1/7, 19.3\%; MOGAD, 0/16, 0\%; AQP4$\operatorname{lgG}^{+}$NMOSD, 2/8, 25.0\%; $\left.p=0.745\right)$.

\section{Brain MRI lesions in the three cohorts}

Brain MRI was performed in 32/37 (86.5\%) cases (A-GFAP-A: 8; MOGAD: 16; AQP4-IgG ${ }^{+}$NMOSD: 8), and contrast-enhanced brain MRI was available for all included patients with A-GFAP-A and MOGAD and 6 of 11 patients with AQP4-IgG+NMOSD. An overview of the key characteristics was shown in Table 3.

In A-GFAP-A cohort, over half of the patients $(5 / 8,62.5 \%$, Fig $2 \mathrm{~A} 1$, arrows) showed bilateral small $(<2 \mathrm{~cm})$, relatively demarcated lesions in ganglia and thalamus, which never occurred in MOGAD $(0 / 16,0 \%$, $p=0.001)$ and AQP4-IgG ${ }^{+}$NMOSD cohort $(0 / 8,0 \%, p=0.026)$, and other lesions involved the cortex $(1 / 8$, $12.5 \%)$ and brainstem $(2 / 8,25 \%$, Fig $2 \mathrm{~A} 2$, arrow). The characteristic linear radial perivascular gadolinium enhancement was found in most of patients $(6 / 9,66.7 \%)$ (Fig 2A3, arrows), but not in MOGAD (0, $0 \%, p<0.001)$ and AQP4-lgG ${ }^{+}$NMOSD $(0,0 \%, p=0.028)$. Diffuse meningeal enhancement was also more common in A-GFAP-A $(8,88.9 \%)$ compared to $\operatorname{MOGAD}(5,29.4 \%, p=0.011)$ and AQP4-lgG ${ }^{+}$NMOSD $(1 / 6$, $16.7 \%, p=0.011)$.

In MOGAD cohort, acute disseminated encephalomyelitis (ADEM)-like lesions (bilateral, asymmetrical, large $[>2 \mathrm{~cm}]$ and poorly demarcated, gadolinium enhancement) occurred frequently $(6 / 16,37.5 \%$, Fig 2B1-B3) but not in A-GFAP-A and AQP4-IgG ${ }^{+} \operatorname{NMOSD}(p=0.02)$. Unilateral cortical T2/FLAIR hyperintense 
lesions $(6 / 16,37.5 \%)$ occurred more frequently in MOGAD, but no significant differences among them ( $A$ GFAP-A: $1 / 8,12.5 \%, p=0.352$; AQP4-IgG ${ }^{+}$NMOSD: $0 / 8,0 \%, p=0.066$ ).

In AQP4-IgG ${ }^{+}$NMOSD cohort, there was more frequent involvement of area postrema $(4 / 8,50 \%$, Fig $2 \mathrm{C} 1)$ and the medulla at sites of high AQP-4 expression (3/8, 37.5\%, Fig 2C2) than MOGAD (area postrema: $0 / 16,0 \%, p=0.007$; medulla: $0 / 16,0 \%, p=0.028$ ) but not significantly different from A-GFAP-A (area postrema: $0 / 8,0 \%, p=0.077$; medulla: $2 / 8,25 \%, p=1.000$ ). Besides, the frequency of gadolinium enhancement to the lesions $(4 / 6,66.7 \%$, Fig $2 \mathrm{C} 3$ ) was more significantly common compared to A-GFAP-A $(0,0 \%, p=0.011)$ and MOGAD without reaching significance $(7,41.2 \%, p=0.371)$.

There was no statistical difference in lesions among the three cohorts available for spinal cord MRI (AGFAP-A: 4/7, 57.1\%; MOGAD: 3/9, 33.3\%; AQP4-IgG ${ }^{+}$NMOSD: 8/11, 72.7\%; $p=0.738$ ) and optic nerve MRI (A-GFAP-A: 1/2, 50\%; MOGAD: 3/6, 50\%; AQP4-IgG ${ }^{+}$NMOSD: $1 / 2,50 \% ; p=1.000$ ).

\section{Discussion}

It has recently been reported that several clinical cases in A-GFAP-A [16, 18], MOGAD [15, 24, 25], and AQP4-IgG+NMOSD $[17,26]$ presented with initial symptoms including headache, fever, meningeal irritation and prominent leukocytosis in CSF are easily misdiagnosed as intracranial infection especially tubercular meningitis, which frequently lead to delayed autoantibody detection and initiation of immunotherapy. Because the neural autoantibody testing is not widely applied in the clinic practice and the available microbiological tests for the diagnosis of tubercular meningitis continue to be a clinical challenge, clinicians meet several challenges in the diagnosis and treatment before the autoantibodies confirmation. Yang et al reported two A-GFAP-A cases mimicking tubercular meningitis, and considered that the increased eosinophil count in the CSF might be related to A-GFAP-A [16]. In our experience, a chronic, relapsing clinical course, along with CSF changes (characteristics of viral or tubercular infection) and some MRI characteristics (such as characteristic radial enhancement, area postrema and ADEM-like lesions) at the same time might be a clue for neural autoantibodies detection. Thus, we recommend the routine screening of neural autoantibodies for those patients with the above suspicious situation. In our study, we investigated clinical profiles of the three CNS demyelinating diseases mimicking intracranial infection as the initial presentation, tried to offer a comparison of the clinical, laboratory and MRI attributes and treatment responses, aiming to provide several clinical implications for the differentiation.

In our study, there was no age predominance among the three cohorts, the mean ages at disease onset were in the patients' $30 \mathrm{~s}$, consistent with previous MOGAD and A-GFAP-A reports [18, 27, 28]. However, AQP4-IgG ${ }^{+}$NMOSD cohorts mimicking intracranial infection were younger and more often male (nearly 90\%) compared to the other two cohorts and previous AQP4-IgG ${ }^{+}$NMOSD reports that were predominantly female $[9,29]$. We assumed that male AQP4-IgG ${ }^{+}$NMOSD patients were more easily initially presented with infectious meningitis-like symptoms than female ones, which need to be further evaluated in larger populations. In addition, we found that several clinical characteristics that distinguished A-GFAP-A from MOGAD and AQP4-IgG+NMOSD included the higher frequencies of 
presence of tremor, fever, meningeal irritation signs and a more severe disease course during the acute attack, which might be clues for GFAP-IgG detection. In addition, the majority responded well to initial immunotherapy at the acute stage, and there was no significance in the immunotherapy strategy choices and responses to acute-stage treatment among the three cohorts, implicating the importance of early immunotherapy initiation.

Upon comparison of CSF analysis in our cohorts, $22.2 \%$ of AQP4-IgG ${ }^{+}$NMOSD cohorts had lymphocytic pleocytosis, albeit to a lesser degree than in A-GFAP-A (88.9\%) and MOGAD (75\%). CSF protein level and the proportion of elevated protein and marked elevated protein level in A-GFAP-A were significantly higher relative to the other two cohorts, similar to previously reported cases $[2,18,30,31]$. Lactate level, a possible marker of disease activity [32] were elevated in $88.9 \%$ of our A-GFAP-A patients, which might be due to increased blood-brain-barrier (BBB) permeability [33]. CSF pleocytosis, elevated protein levels and lactate levels, three CSF features of bacterial CNS infection, might lead to a misdiagnosis of infectious disease. It was observed that marked deposits of IgM were histopathological characteristics in NMOSD lesions [34], and IgM was generally stronger complement activators than IgG in AQP4-IgG ${ }^{+}$NMOSD, in which tissue damage was partly exerted by complement activation [35]. In our cohorts, significant increase in CSF levels of IgG, IgM and IgA, elevated IgG levels were found in A-GFAP-A compared to MOGAD and AQP4-IgG ${ }^{+}$NMOSD cohorts, which might be clues for the differentiation as well, though the specificity of intrathecal production of $\lg$, IgM and IgA is still not fully elucidated. Furthermore, over half of patients with AQP4-lgG ${ }^{+}$NMOSD had serological signs of systemic autoimmunity in ANA and SSA, while none was observed in A-GFAP-A and MOGAD. Given the above findings, we demonstrated a differential pattern of CSF analysis by comparing to the three cohorts.

The current study also confirmed several radiological characteristics that distinguished the three diseases presented with infectious meningitis-like symptoms as the initial manifestation. Besides previously reported characteristic linear radial perivascular gadolinium enhancement $[2,18]$, distinct small $(<2 \mathrm{~cm})$, symmetrical T2/FLAIR lesions in ganglia and thalamus and diffuse meningeal T1-enhancement were seen in over half of A-GFAP-A patients. Notably, ADEM-like lesions (bilateral, asymmetrical, large [>2 cm] and poorly demarcated) occurred frequently in MOGAD but never in the other two cohorts, and unilateral cortical T2/FLAIR lesions were more frequently seen in MOGAD, in line with our previous study [36], although not statistically significant due to small case numbers. The underlying reason may be due to an abundance of MOG in these highly myelinated white matter tracts [37]. Patients in AQP4-IgG ${ }^{+} \mathrm{NMOSD}^{-}$ were more vulnerable to characteristic demyelinating T2-lesions in area postrema at sites of high AQP-4 expression and T1-enhancement limited to the lesions without diffuse meningeal enhancement [38, 39]. In summary, the above radiological characteristics could be differential supportive evidence and clues.

\section{Conclusion}

In conclusion, we conducted a comparison of the clinical, immunological and radiological features of 37 patients who presented with initial symptoms mimicking infectious meningitis but were finally diagnosed 
as A-GFAP-A, MOGAD and AQP4-IgG ${ }^{+}$NMOSD. Our findings for the first time confirmed that the symptom of tremor, a more severe disease course, higher CSF immunological profiles and ganglia bilateral symmetrical lesions, diffuse meningeal enhancement were distinct features in A-GFAP-A, while ADEM-like lesions occurred only in MOGAD, providing supportive evidence for the differential diagnosis. Our study has several limitations. In AQP4-IgG ${ }^{+}$NMOSD cohort, 3 of 11 patients $(27.3 \%)$ were not the first attack and received immunosuppressant treatment in the intermission of attack, who were prone to suffer infectious situation. It was of difficulty to differentiate the relapse and infection caused by immunotherapy. Besides, the study is limited by the single-center retrospective design and small sample size, and the underlying pathogenic roles are not elucidated, prospective multi-center studies with larger sample size will be needed.

\section{Declarations}

\section{Data Availability Statement}

The datasets analyzed for this study are included in the article/Supplementary Material.

\section{Conflict of Interest}

The authors declare that the research was conducted in the absence of any commercial or financial relationships that could be construed as a potential conflict of interest.

\section{Consent for publication}

Not applicable.

\section{Author Contributions}

JX, CQ, YT and MC were responsible for acquiring and analyzing the clinical data. SZ was responsible for collecting and summarizing radiological characteristics. JX was responsible for drafting the manuscript, tables and figures. CM and KS performed the statistical analysis. CQ, DT provided funding, design, overall supervision for this study. DT had full access to all the data in the study and took responsibility for the integrity of the data and the accuracy of the data analysis. All the authors reviewed and approved the final manuscript.

\section{Funding}

The study was supported by Tongji Hospital (HUST) Foundation for Excellent Young Scientist (Grant No. 2020YQ06).

\section{Acknowledgments}

We would like to thank Wuhan Kindstar Diagnostics Co., Ltd, Wuhan, China, for technical support. 


\section{References}

1. Dalmau J, Graus F: Antibody-Mediated Encephalitis. N Engl J Med 2018, 378:840-851.

2. Fang B, McKeon A, Hinson SR, Kryzer TJ, Pittock SJ, Aksamit AJ, Lennon VA: Autoimmune Glial Fibrillary Acidic Protein Astrocytopathy: A Novel Meningoencephalomyelitis. JAMA Neurol 2016, 73:12971307.

3. Lucchinetti CF, Guo Y, Popescu BF, Fujihara K, Itoyama Y, Misu T: The pathology of an autoimmune astrocytopathy: lessons learned from neuromyelitis optica. Brain Pathol 2014, 24:83-97.

4. Reindl M, Di Pauli F, Rostásy K, Berger T: The spectrum of MOG autoantibody-associated demyelinating diseases. Nat Rev Neurol 2013, 9:455-461.

5. Pröbstel AK, Rudolf G, Dornmair K, Collongues N, Chanson JB, Sanderson NS, Lindberg RL, Kappos L, de Seze J, Derfuss T: Anti-MOG antibodies are present in a subgroup of patients with a neuromyelitis optica phenotype. J Neuroinflammation 2015, 12:46.

6. Peschl P, Bradl M, Höftberger R, Berger T, Reindl M: Myelin Oligodendrocyte Glycoprotein: Deciphering a Target in Inflammatory Demyelinating Diseases. Front Immunol 2017, 8:529.

7. Wingerchuk DM, Lennon VA, Lucchinetti CF, Pittock SJ, Weinshenker BG: The spectrum of neuromyelitis optica. Lancet Neurol 2007, 6:805-815.

8. Zamvil SS, Slavin AJ: Does MOG Ig-positive AQP4-seronegative opticospinal inflammatory disease justify a diagnosis of NMO spectrum disorder? Neurol Neuroimmunol Neuroinflamm 2015, 2:e62.

9. Borisow N, Mori M, Kuwabara S, Scheel M, Paul F: Diagnosis and Treatment of NMO Spectrum Disorder and MOG-Encephalomyelitis. Front Neurol 2018, 9:888.

10. McKeon A, Benarroch EE: Glial fibrillary acid protein: Functions and involvement in disease. Neurology 2018, 90:925-930.

11. Salama S, Khan M, Shanechi A, Levy M, Izbudak I: MRI differences between MOG antibody disease and AQP4 NMOSD. Mult Scler 2020, 26:1854-1865.

12. Mariano R, Messina S, Kumar K, Kuker W, Leite MI, Palace J: Comparison of Clinical Outcomes of Transverse Myelitis Among Adults With Myelin Oligodendrocyte Glycoprotein Antibody vs Aquaporin-4 Antibody Disease. JAMA Netw Open 2019, 2:e1912732.

13. Rempe T, Tarhan B, Rodriguez E, Viswanathan VT, Gyang TV, Carlson A, Tuna IS, Rees J: Anti-MOG associated disorder-Clinical and radiological characteristics compared to AQP4-IgG+ NMOSD-A singlecenter experience. Mult Scler Relat Disord 2021, 48:102718. 
14. Banks SA, Morris PP, Chen JJ, Pittock SJ, Sechi E, Kunchok A, Tillema JM, Fryer JP, Weinshenker BG, Krecke KN, et al: Brainstem and cerebellar involvement in MOG-IgG-associated disorder versus aquaporin4-IgG and MS. J Neurol Neurosurg Psychiatry 2020.

15. Narayan RN, Wang C, Sguigna P, Husari K, Greenberg B: Atypical Anti-MOG syndrome with aseptic meningoencephalitis and pseudotumor cerebri-like presentations. Mult Scler Relat Disord 2019, 27:30-33.

16. Yang $X$, Zhang C, Zhang J, Chen G, Zhao L, Yang P, Li H, Long Y: Autoimmune glial fibrillary acidic protein astrocytopathy mimics infectious meningitis: Two case reports. Mult Scler Relat Disord 2020, 45:102350.

17. Wang JY, Wang K, Chen XW, Wang JW, Zhang K, Xu MW, Luo BY: Meningoencephalitis as an initial manifestation of neuromyelitis optica spectrum disorder. Mult Scler 2013, 19:639-643.

18. Xiao J, Chen X, Shang K, Tang Y, Chen M, Deng G, Qin C, Tian DS: Clinical, neuroradiological, diagnostic and prognostic profile of autoimmune glial fibrillary acidic protein astrocytopathy: A pooled analysis of 324 cases from published data and a single-center retrospective study. $J$ Neuroimmunol 2021, 360:577718.

19. Jarius S, Paul F, Aktas O, Asgari N, Dale RC, de Seze J, Franciotta D, Fujihara K, Jacob A, Kim HJ, et al: MOG encephalomyelitis: international recommendations on diagnosis and antibody testing. $J$ Neuroinflammation 2018, 15:134.

20. Wingerchuk DM, Banwell B, Bennett JL, Cabre P, Carroll W, Chitnis T, de Seze J, Fujihara K, Greenberg $B$, Jacob A, et al: International consensus diagnostic criteria for neuromyelitis optica spectrum disorders. Neurology 2015, 85:177-189.

21. Kunchok A, Zekeridou A, McKeon A: Autoimmune glial fibrillary acidic protein astrocytopathy. Curr Opin Neuro/ 2019, 32:452-458.

22. Waters PJ, McKeon A, Leite MI, Rajasekharan S, Lennon VA, Villalobos A, Palace J, Mandrekar JN, Vincent A, Bar-Or A, Pittock SJ: Serologic diagnosis of NMO: a multicenter comparison of aquaporin-4-IgG assays. Neurology 2012, 78:665-671; discussion 669.

23. Dubey D, Pittock SJ, Krecke KN, Morris PP, Sechi E, Zalewski NL, Weinshenker BG, Shosha E, Lucchinetti CF, Fryer JP, et al: Clinical, Radiologic, and Prognostic Features of Myelitis Associated With Myelin Oligodendrocyte Glycoprotein Autoantibody. JAMA Neurol 2019, 76:301-309.

24. Wang L, ZhangBao J, Zhou L, Zhang Y, Li H, Li Y, Huang Y, Wang M, Lu C, Lu J, et al: Encephalitis is an important clinical component of myelin oligodendrocyte glycoprotein antibody associated demyelination: a single-center cohort study in Shanghai, China. Eur J Neurol 2019, 26:168-174.

25. Otani T, Irioka T, Igarashi S, Kaneko K, Takahashi T, Yokota T: Self-remitting cerebral cortical encephalitis associated with myelin oligodendrocyte glycoprotein antibody mimicking acute viral 
encephalitis: A case report. Mult Scler Relat Disord 2020, 41:102033.

26. Wang L, Su HJ, Song GJ: A rare case of short-lasting unilateral neuralgiform headache with conjunctival injection and tearing with progression to neuromyelitis optica spectrum disorder. $J$ Int Med Res 2020, 48:300060520964349.

27. Cobo-Calvo A, Ruiz A, Maillart E, Audoin B, Zephir H, Bourre B, Ciron J, Collongues N, Brassat D, Cotton $F$, et al: Clinical spectrum and prognostic value of CNS MOG autoimmunity in adults: The MOGADOR study. Neurology 2018, 90:e1858-e1869.

28. Jurynczyk M, Messina S, Woodhall MR, Raza N, Everett R, Roca-Fernandez A, Tackley G, Hamid S, Sheard A, Reynolds G, et al: Clinical presentation and prognosis in MOG-antibody disease: a UK study. Brain 2017, 140:3128-3138.

29. Höftberger R, Sepulveda M, Armangue T, Blanco Y, Rostásy K, Calvo AC, Olascoaga J, Ramió-Torrentà L, Reindl M, Benito-León J, et al: Antibodies to MOG and AQP4 in adults with neuromyelitis optica and suspected limited forms of the disease. Mult Scler 2015, 21:866-874.

30. de Mol CL, Wong Y, van Pelt ED, Wokke B, Siepman T, Neuteboom RF, Hamann D, Hintzen RQ: The clinical spectrum and incidence of anti-MOG-associated acquired demyelinating syndromes in children and adults. Mult Scler 2020, 26:806-814.

31. Kaneko K, Sato DK, Nakashima I, Ogawa R, Akaishi T, Takai Y, Nishiyama S, Takahashi T, Misu T, Kuroda $\mathrm{H}$, et al: CSF cytokine profile in MOG-IgG+ neurological disease is similar to AQP4-IgG+ NMOSD but distinct from MS: a cross-sectional study and potential therapeutic implications. $J$ Neurol Neurosurg Psychiatry 2018, 89:927-936.

32. Jarius S, Paul F, Franciotta D, Ruprecht K, Ringelstein M, Bergamaschi R, Rommer P, Kleiter I, Stich O, Reuss $\mathrm{R}$, et al: Cerebrospinal fluid findings in aquaporin-4 antibody positive neuromyelitis optica: results from 211 lumbar punctures. J Neurol Sci 2011, 306:82-90.

33. Posner JB, Plum F: Independence of blood and cerebrospinal fluid lactate. Arch Neurol 1967, 16:492496.

34. Lucchinetti CF, Mandler RN, McGavern D, Bruck W, Gleich G, Ransohoff RM, Trebst C, Weinshenker B, Wingerchuk D, Parisi JE, Lassmann H: A role for humoral mechanisms in the pathogenesis of Devic's neuromyelitis optica. Brain 2002, 125:1450-1461.

35. Saadoun S, Waters P, Bell BA, Vincent A, Verkman AS, Papadopoulos MC: Intra-cerebral injection of neuromyelitis optica immunoglobulin $\mathbf{G}$ and human complement produces neuromyelitis optica lesions in mice. Brain 2010, 133:349-361.

36. Tao R, Qin C, Chen M, Yu HH, Wu LJ, Bu BT, Tian DS: Unilateral cerebral cortical encephalitis with epilepsy: a possible special phenotype of MOG antibody-associated disorders. Int J Neurosci 2020, 
130:1161-1165.

37. Solly SK, Thomas JL, Monge M, Demerens C, Lubetzki C, Gardinier MV, Matthieu JM, Zalc B:

Myelin/oligodendrocyte glycoprotein (MOG) expression is associated with myelin deposition. Glia 1996, 18:39-48.

38. Kim W, Park MS, Lee SH, Kim SH, Jung IJ, Takahashi T, Misu T, Fujihara K, Kim HJ: Characteristic brain magnetic resonance imaging abnormalities in central nervous system aquaporin-4 autoimmunity. Mult Scler 2010, 16:1229-1236.

39. Chan KH, Tse CT, Chung CP, Lee RL, Kwan JS, Ho PW, Ho JW: Brain involvement in neuromyelitis optica spectrum disorders. Arch Neurol 2011, 68:1432-1439.

\section{Tables}

Table 1 Comparison of demographic and clinical characteristics among the three cohorts 
No. $(\%)$

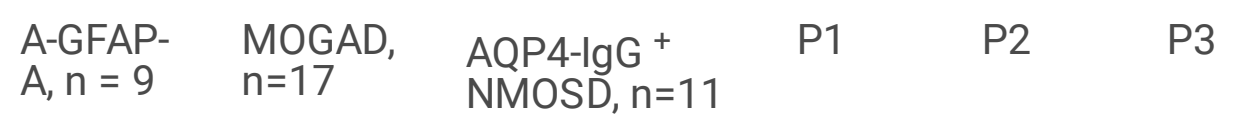

Demographics

\begin{tabular}{lllllll}
$\begin{array}{l}\text { Median age at onset, years } \\
\text { (range) }\end{array}$ & $\begin{array}{l}39(14- \\
68)\end{array}$ & $\begin{array}{l}32(13- \\
61)\end{array}$ & $37(17-67)$ & 0.251 & 0.766 & 0.377 \\
\hline Female, $\mathrm{n}(\%)$ & $6(66.7)$ & $\begin{array}{l}12 \\
(70.6)\end{array}$ & $1(9.1)$ & 1.000 & $0.017^{\star}$ & $0.002^{\star \star \star}$ \\
\hline $\begin{array}{l}\text { Duration of symptoms, } \\
\text { days (range) }\end{array}$ & $\begin{array}{l}93(5- \\
730)\end{array}$ & $\begin{array}{l}18(1- \\
60)\end{array}$ & $17(1-60)$ & 0.128 & 0.159 & 0.989 \\
\hline $\begin{array}{l}\text { Intensive care unit stay, } \mathrm{n} \\
(\%)\end{array}$ & $2(22.2)$ & $1(5.9)$ & $0(0)$ & 0.268 & 0.189 & 1.000 \\
\hline
\end{tabular}

Clinical features

\begin{tabular}{|c|c|c|c|c|c|c|}
\hline Fever, n (\%) & $9(100)$ & $\begin{array}{l}14 \\
(82.4)\end{array}$ & $5(45.5)$ & 0.529 & $0.014^{\star}$ & 0.095 \\
\hline Headache, n (\%) & $6(66.7)$ & $\begin{array}{l}16 \\
(94.1)\end{array}$ & 8 (72.7) & 0.104 & 1.000 & 0.269 \\
\hline $\begin{array}{l}\text { Nuchal rigidity/ positive } \\
\text { Kernig sign, } \mathrm{n}(\%)\end{array}$ & $7(77.8)$ & $5(29.4)$ & 2 (18.2) & $0.038^{*}$ & $0.022^{*}$ & 0.668 \\
\hline Tremor, n (\%) & $4(44.4)$ & $1(5.9)$ & $0(0)$ & $0.034^{*}$ & $0.026^{*}$ & 1.000 \\
\hline $\begin{array}{l}\text { Median mRS at attack } \\
\text { nadir (range) }\end{array}$ & $3.7(2-5)$ & $2.4(1-5)$ & $2.2(0-5)$ & 0.058 & $0.04^{\star}$ & 0.704 \\
\hline
\end{tabular}

Acute treatment

\begin{tabular}{lllllll}
\hline IVMP alone, n (\%) & $5(55.6)$ & $\begin{array}{l}12 \\
(70.6)\end{array}$ & $5(45.5)$ & 0.667 & 1.000 & 0.248 \\
\hline IVMP + PLEX, n (\%) & $0(0)$ & $0(0)$ & $1(9.1)$ & NA & 1.000 & 0.393 \\
\hline IVMP+ IVIG, n (\%) & $4(44.4)$ & $2(11.8)$ & $3(27.3)$ & 0.138 & 0.642 & 0.353 \\
\hline No treatment, n (\%) & $0(0)$ & $3(17.6)$ & $1(9.1)$ & 0.294 & 1.000 & 1.000
\end{tabular}

Outcome

\begin{tabular}{|cclcccc|}
$\begin{array}{c}\text { Reponses to acute-stage } \\
\text { immunotherapy, } \mathrm{n}(\%)\end{array}$ & $9(100)$ & $\begin{array}{l}14 \\
(82.4)\end{array}$ & $8(72.7)$ & 0.529 & 0.218 & 0.653 \\
\hline $\begin{array}{c}\text { Median mRS after acute } \\
\text { treatment (range) }\end{array}$ & $1.7(0-3)$ & $0.9(0-5)$ & $1.5(0-4)$ & 0.193 & 0.840 & 0.247 \\
\hline
\end{tabular}

Abbreviations: A-GFAP-A, autoimmune glial fibrillary acidic protein astrocytopathy; AQP-4,aquaporin-4; IVIG, intravenous immunoglobulin; IVMP, intravenous methylprednisolone; MOGAD, myelin 
oligodendrocyte glycoprotein antibody-associated disorder; mRS, modified Rankin Scale; NA, not applicable; NMOSD, neuromyelitis optica spectrum disorders; PLEX, plasma exchange; P1, A-GFAP-A compared with MOGAD; P2, A-GFAP-A compared with AQP4-IgG +NMOSD; P3, MOGAD compared with AQP4-IgG + NMOSD; $*, p<0.05 ; * \star, p<0.01 ; * \star \star, p<0.005$.

Table 2: Comparison of CSF findings among the three cohorts 
№. (\%)

\begin{tabular}{|c|c|c|}
\hline $\begin{array}{l}\text { A-GFAP-A, } n= \\
9\end{array}$ & $\begin{array}{l}\text { MOGAD, } \\
n=16\end{array}$ & $\begin{array}{l}\text { AQP4-IgG + } \\
\text { NMOSD, } n=9\end{array}$ \\
\hline
\end{tabular}

\begin{tabular}{lllllll} 
WBC, $\times 10^{6} / \mathrm{L}$ & $272(0-1600)$ & $99(0-480)$ & $12(0-48)$ & 0.133 & $0.049 *$ & 0.446 \\
$\begin{array}{l}\text { Elevated WBC } \\
\text { count, }>\end{array}$ & $8(88.9)$ & $12(75.0)$ & $2(22.2)$ & 0.621 & $0.015^{*}$ & $0.033^{*}$ \\
$10 \times 10^{6} / \mathrm{L}(\%)$ & & & & & \\
$\begin{array}{l}\text { Marked elevated } \\
\text { WBC count, } \\
50 \times 10^{6} / \mathrm{L}(\%)\end{array}$ & $6(66.7)$ & $9(56.2)$ & $2(22.2)$ & 0.691 & 0.153 & 0.208 \\
\hline
\end{tabular}

$\begin{array}{lllllll}\text { Protein, } \mathrm{mg} / \mathrm{L} & 1490.7 \pm 871.2 & 606.7 \pm 379.4 & 441.8 \pm 178.0 & 0.000^{\star \star \star} & 0.000^{\star \star \star} & 0.455 \\ \begin{array}{l}\text { Elevated protein } \\ \text { level, }>450 \mathrm{mg} / \mathrm{L}\end{array} & 9(100) & 8(50.0) & 3(33.3) & 0.012^{\star} & 0.009 * \star & 0.677\end{array}$
(\%)

\begin{tabular}{lllllll}
$\begin{array}{l}\text { Marked elevated } \\
\text { protein level, } \\
>1 \mathrm{~g} / \mathrm{L}(\%)\end{array}$ & $7(77.8)$ & $3(18.8)$ & $0(0)$ & $0.009^{\star \star}$ & $0.002^{\star \star \star}$ & 0.280 \\
\hline $\mathrm{LDH}, \mathrm{U} / \mathrm{L}$ & $53.9 \pm 37.2$ & $21.7 \pm 13.4$ & $45.9 \pm 66.2$ & 0.061 & 0.672 & 0.153 \\
\hline $\begin{array}{l}\text { Elevated LDH } \\
\text { level, }>40 \mathrm{U} / \mathrm{L}\end{array}$ & $4(44.4)$ & $1(6.2)$ & $2(22.2)$ & $0.040 *$ & 0.620 & 0.530 \\
\hline
\end{tabular}

(\%)

\begin{tabular}{lcccccc}
$\begin{array}{l}\text { Lactic acid, } \\
\mathrm{mmol} / \mathrm{L}\end{array}$ & $3.43 \pm 0.81$ & $2.15 \pm 0.62$ & $2.40 \pm 0.66$ & $0.000^{\star \star \star}$ & $0.003^{\star \star \star}$ & 0.380 \\
$\begin{array}{l}\text { Elevated lactic } \\
\text { acid level, }>2.4 \\
\mathrm{mmol} / \mathrm{L}(\%)\end{array}$ & $8(88.9)$ & $3(18.8)$ & $4(44.4)$ & $0.002^{\star \star \star}$ & 0.131 & 0.205 \\
\hline
\end{tabular}

\begin{tabular}{lllllll}
$\begin{array}{l}\text { Positive OB, } \mathrm{n} \\
(\%)\end{array}$ & $2 / 7(28.6)$ & $0 / 12(0)$ & $0 / 7(0)$ & 0.124 & 0.462 & NA \\
\hline IgG index & $0.8 \pm 0.3(\mathrm{n}=7)$ & $\begin{array}{l}0.7 \pm 0.1 \\
(\mathrm{n}=12)\end{array}$ & $\begin{array}{l}0.7 \pm 0.1 \\
(\mathrm{n}=7)\end{array}$ & 0.116 & 0.193 & 0.901 \\
\hline
\end{tabular}

Elevated IgG

index, $>0.7$ (\%)

\begin{tabular}{lllllll} 
Albumin quotient & $\begin{array}{l}13.7 \pm 7.2 \\
(\mathrm{n}=7)\end{array}$ & $\begin{array}{l}8.8 \pm 8.4 \\
(\mathrm{n}=12)\end{array}$ & $\begin{array}{l}6.6 \pm 2.7 \\
(\mathrm{n}=7)\end{array}$ & 0.162 & 0.074 & 0.518 \\
$\begin{array}{l}\text { Elevated } \\
\text { albumin quotient, } \\
>6.5(\%)\end{array}$ & $6 / 7(85.7)$ & $4 / 12(33.3)$ & $3 / 7(42.9)$ & 0.057 & 0.266 & 1.000 \\
\hline IgG, $\mathrm{mg} / \mathrm{L}$ & $130.9 \pm 60.4$ & $77.9 \pm 71.3$ & $53.2 \pm 30.3$ & $0.043^{*}$ & $0.01^{*}$ & 0.333 \\
$\begin{array}{l}\text { Elevated } \mathrm{lgG} \\
\text { level, }>58.6 \mathrm{mg} / \mathrm{L}\end{array}$ & $9(100)$ & $6(37.5)$ & $2(22.2)$ & $0.003^{* * *}$ & $0.002^{\star * *}$ & 0.661 \\
\hline
\end{tabular}


$(\%)$

\begin{tabular}{|lllllll}
\hline $\operatorname{lgM}, \mathrm{mg} / \mathrm{L}$ & $8.6 \pm 6.1$ & $2.7 \pm 2.9$ & $2.1 \pm 3.9$ & $0.002^{\star \star \star}$ & $0.003^{\star \star \star}$ & 0.745 \\
\hline $\begin{array}{l}\text { Elevated } \mathrm{IgM} \\
\text { level, }>7.0 \mathrm{mg} / \mathrm{L} \\
(\%)\end{array}$ & $4(44.4)$ & $2(12.5)$ & $1(11.1)$ & 0.142 & 0.294 & 1.000 \\
\hline $\operatorname{lgA}, \mathrm{mg} / \mathrm{L}$ & $23.0 \pm 11.4$ & $11.3 \pm 12.1$ & $5.2 \pm 5.0$ & $0.012^{\star}$ & $0.001^{\star \star \star}$ & 0.181 \\
\hline $\begin{array}{l}\text { Elevated IgA } \\
\text { level, }>4.4 \mathrm{mg} / \mathrm{L} \\
(\%)\end{array}$ & $9(100)$ & $11(68.8)$ & $2(22,2)$ & 0.123 & $0.002^{\star \star \star}$ & $0.041^{\star}$ \\
\hline
\end{tabular}

Abbreviations: A-GFAP-A, autoimmune glial fibrillary acidic protein astrocytopathy; AQP-4,aquaporin-4; CSF, cerebrospinal fluid; LDH, dehydrogenase; MOGAD, myelin oligodendrocyte glycoprotein antibodyassociated disorder; NA, not applicable; NMOSD, neuromyelitis optica spectrum disorders; OB, oligoclonal band; $p 1$, A-GFAP-A compared with MOGAD; $p 2$, A-GFAP-A compared with AQP4-IgG +NMOSD; $p 3$, MOGAD compared with AQP4-IgG + NMOSD; *, $p<0.05 ; * \star, p<0.01 ; * \star \star, p<0.005$.

Table 3: Comparison of MRI features among the three cohorts 
No. $(\%)$

$\begin{array}{llllll}\text { A-GFAP- } & \text { MOGAD, } & \text { AQP4-IgG }+ & p 1 & p 2 & p 3 \\ \mathrm{~A}, \mathrm{n}=9 & \mathrm{n}=17 & \text { NMOSD, } \mathrm{n}=11 & & & \end{array}$

Brain T2 lesions

\begin{tabular}{|c|c|c|c|c|c|c|}
\hline $\begin{array}{l}\text { Medulla lesion present, } \\
\mathrm{n}(\%)\end{array}$ & $\begin{array}{l}2 / 8 \\
(25.0)\end{array}$ & $0 / 6(0)$ & $3 / 8$ (37.5) & 0.101 & 1.000 & $0.028^{*}$ \\
\hline $\begin{array}{l}\text { Area postrema lesion } \\
\text { present, } n(\%)\end{array}$ & $0 / 8(0)$ & $0 / 16(0)$ & $4 / 8(50.0)$ & NA & 0.077 & $0.007^{\star * *}$ \\
\hline $\begin{array}{l}\text { Bilateral ganglia lesion } \\
\text { present, } \mathrm{n}(\%)\end{array}$ & $\begin{array}{l}5 / 8 \\
(62.5)\end{array}$ & $0 / 16(0)$ & $0 / 8(0)$ & $0.001^{\star \star}$ & $0.026 *$ & NA \\
\hline $\begin{array}{l}\text { ADEM-like lesion } \\
\text { present, } n(\%)\end{array}$ & $0 / 8(0)$ & $\begin{array}{l}6 / 16 \\
(37.5)\end{array}$ & $0 / 8(0)$ & 0.066 & NA & 0.066 \\
\hline $\begin{array}{l}\text { Unilateral cortical } \\
\text { lesions, } \mathrm{n}(\%)\end{array}$ & $\begin{array}{l}1 / 8 \\
(12.5)\end{array}$ & $\begin{array}{l}6 / 16 \\
(37.5)\end{array}$ & $0 / 8(0)$ & 0.352 & 1.000 & 0.066 \\
\hline $\begin{array}{l}\text { Brain T1-enhancment } \\
\text { lesions, } \mathrm{n}(\%)\end{array}$ & $8(88.9)$ & $11(64.7)$ & $3 / 6(50.0)$ & 0.357 & 0.235 & 0.643 \\
\hline $\begin{array}{l}\text { Meningeal } \\
\text { enhancement, n (\%) }\end{array}$ & $8(88.9)$ & $5(29.4)$ & $1 / 6(16.7)$ & $0.011^{\star}$ & $0.011^{\star}$ & 1.000 \\
\hline $\begin{array}{l}\text { Partial lesion } \\
\text { enhancement, } n(\%)\end{array}$ & $0(0)$ & $7(41.2)$ & $4 / 6(66.7)$ & 0.058 & $0.011 *$ & 0.371 \\
\hline $\begin{array}{l}\text { "Radial enhancement", } \\
\text { n (\%) }\end{array}$ & $6(66.7)$ & $0(0)$ & $0 / 6(0)$ & $0.000 * \star \star$ & $0.028 *$ & NA \\
\hline $\begin{array}{l}\text { Spinal cord lesion } \\
\text { present at attack, n (\%) }\end{array}$ & $\begin{array}{l}4 / 7 \\
(57.1)\end{array}$ & $\begin{array}{l}3 / 9 \\
(33.3)\end{array}$ & 8 (72.7) & 0.615 & 0.627 & 0.175 \\
\hline $\begin{array}{l}\text { Optic nerve lesion } \\
\text { present at attack, } \mathrm{n}(\%)\end{array}$ & $\begin{array}{l}1 / 2 \\
(50.0)\end{array}$ & $\begin{array}{l}3 / 6 \\
(50.0)\end{array}$ & $1 / 2(50.0)$ & 1.000 & 1.000 & 1.000 \\
\hline
\end{tabular}

Abbreviations: ADEM, acute disseminated encephalomyelitis; A-GFAP-A, autoimmune glial fibrillary acidic protein astrocytopathy; AQP-4,aquaporin-4; MOGAD, myelin oligodendrocyte glycoprotein antibodyassociated disorder; MRI, magnetic resonance imaging; NA, not applicable; NMOSD, neuromyelitis optica spectrum disorders; $p 1$, A-GFAP-A compared with MOGAD; $p 2$, A-GFAP-A compared with AQP4-IgG +NMOSD; $p 3$, MOGAD compared with AQP4-IgG + NMOSD; *, $p<0.05 ; * \star, ~ p<0.01 ; * \star \star, ~ p<0.005$.

\section{Figures}



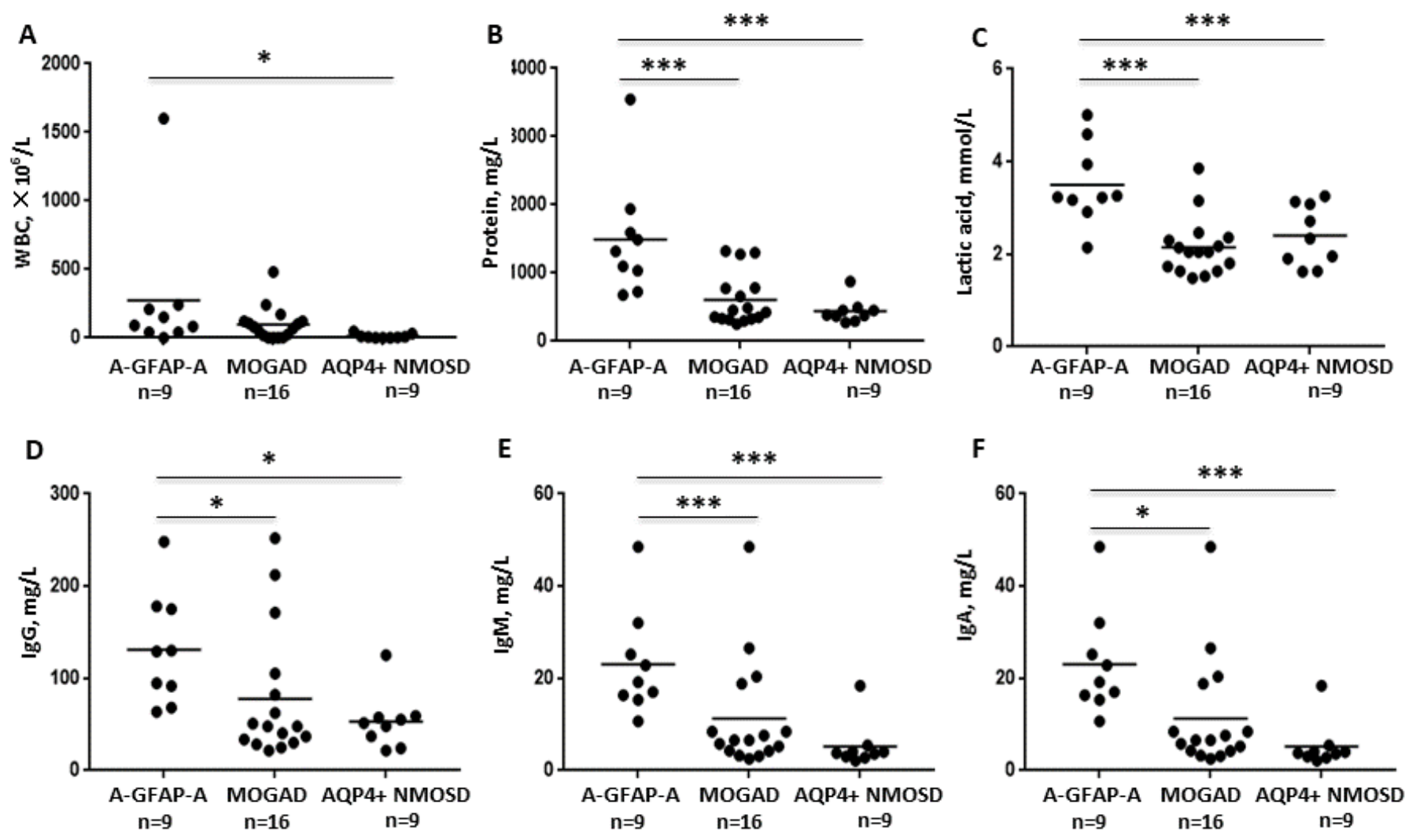

\section{Figure 1}

Comparative analysis of the three cohorts in terms of CSF findings

The CSF levels of WBC counts (A), protein (B), lactic acid (C), IgG (D), IgM (E) and IgA (F) were compared in the three cohorts. Wilcoxon rank sum test was used for statistical analysis. * refers to $p<0.05$; $\star \star$ refers to $p<0.01$; $* \star \star *$ refers to $p<0.005$. 

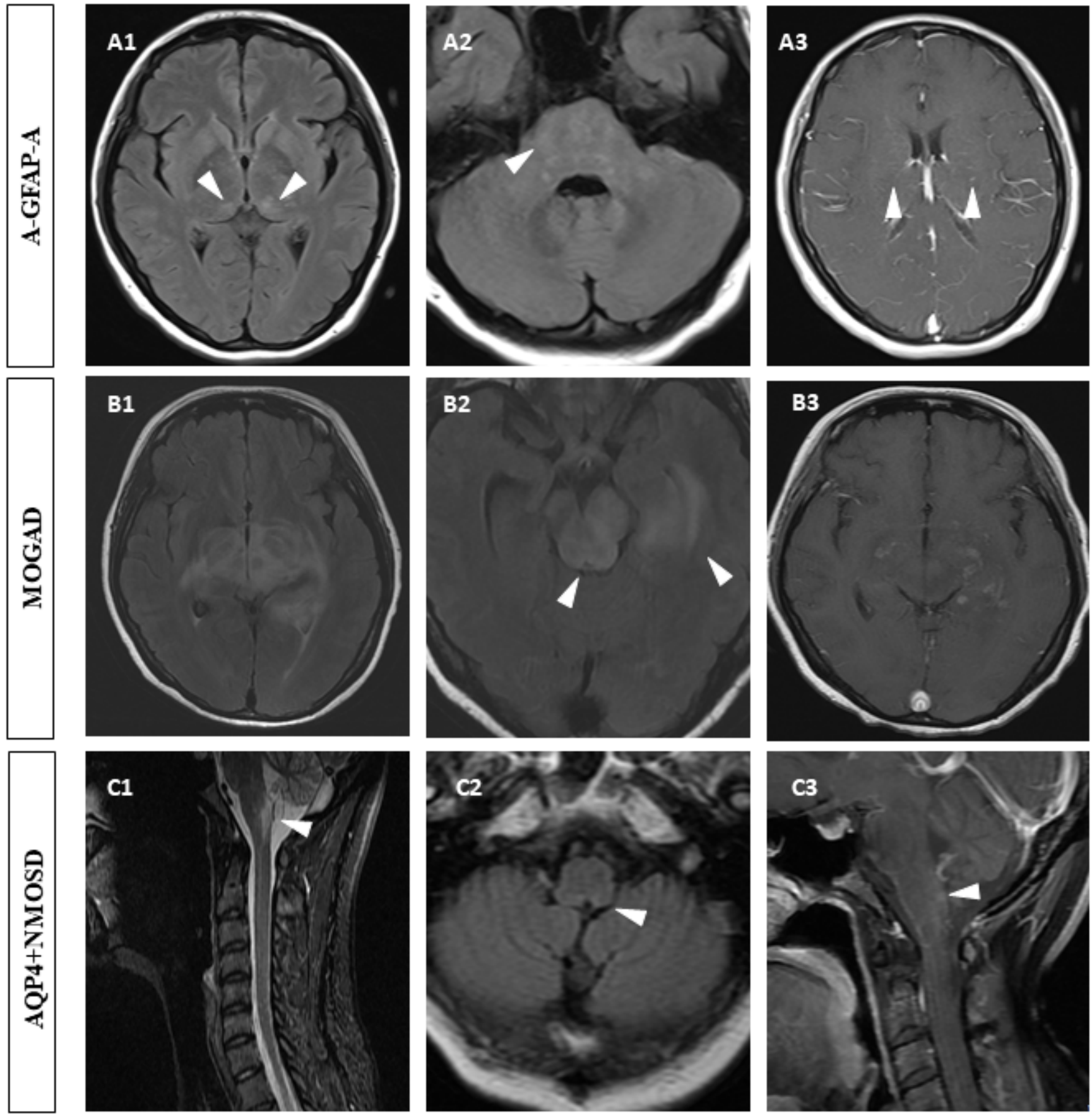

Figure 2

Representative examples of brain MRI lesions in A-GFAP-A (A), MOGAD (B) and AQP4-IgG ${ }^{+}$NMOSD (C).

In patients with A-GFAP-A, axial section shows abnormal T2-FLAIR hyperintensity lesions on bilateral basal ganglia and the posterior thalamus (A1, arrowheads), patchy T2-hyperintensity lesions in brainstem (A2, arrowhead) and accompanied by characteristic linear radial enhancement pattern on postgadolinium T1-weighted images (A3, arrowheads). In patients with MOGAD, axial T2/FLAIR-weighted section demonstrates bilateral diffuse lesions in the thalamus, corpus callosum (B1) and midbrain (B2, 
arrowheads), with associated enhancement on T1-weighted sequences (B3). In patients with AQP4$\mathrm{IgG}+\mathrm{NMOSD}$, lesions of area postrema in the dorsal medulla demonstrates in sagittal (C1, arrowhead), axial (C2, arrowhead) T2/FLAIR-weighted section and gadolinium-enhanced T1- weighted images (C3, arrowhead).

\section{Supplementary Files}

This is a list of supplementary files associated with this preprint. Click to download.

- TableS1.xIsx

- TableS2.xIsx

- TableS3.xIsx 